Pediatrics

\title{
Cross-cultural comparisons of motor competence in southern Brazilian and Portuguese schoolchildren
}

\author{
Fábio Saraiva Flôres ${ }^{1,2}$ (D), Luis Paulo Rodrigues ${ }^{3}$ (D), Carlos Luz $^{4}$ (D), Rita Cordovil ${ }^{5}$ \\ ${ }^{1}$ Universidade de Lisboa, Faculdade de Motricidade Humana, Lisboa, Portugal; ${ }^{2}$ Instituto \\ Piaget, Kinesiolab, Almada, Portugal; ${ }^{3}$ Instituto Politécnico de Viana do Castelo, Escola \\ Superior Desporto e Lazer de Melgaço, Centro de Investigação em Desporto, Saúde e \\ Desenvolvimento Humano, Melgaço, Portugal; ${ }^{4}$ Instituto Politécnico de Lisboa, Escola Superior \\ de Educação de Lisboa, Campus de Benfica, Lisboa, Portugal; ${ }^{5}$ Universidade de Lisboa, \\ Faculdade de Motricidade Humana, Centro Interdisciplinar de Performance Humana, Lisboa, \\ Portugal.
}

Associate Editor: Mariana Ferreira de Souza, Universidade Federal do Vale do São Francisco, Petrolina, PE, Brasil.

\begin{abstract}
Aim: This study aimed to compare the MC levels of Brazilian and Portuguese schoolchildren from 4 to 11 years. Methods: One hundred and forty-eight Brazilian children were evaluated using the Motor Competence Assessment (MCA) instrument and were later compared to the existent normative values of Portuguese children for a similar age range. Results: Our findings showed that MC increased with age, and boys outperformed girls, especially in the older age group. The distribution of the Brazilian children showed that while Brazilian boys perform above Portuguese normative values in 4 of the 6 tasks of the MCA, Brazilian girls perform below those values in all tasks, except for the standing long jump. Conclusion: The differences found, especially in girls, may be related to differences in the Physical Education curricula and how school recess periods are used.
\end{abstract}

Keywords: motor assessment, children, competence, school, physical education.

\section{Introduction}

Motor competence (MC) is understood as an underlying capacity that relates to a person's ability to perform on a broad range of motor skills, such as locomotion, stabilization, and object manipulation, that are fundamental for the acquisition of specialized movements in future life $\mathrm{e}^{1,2}$. Its development occurs along with lifespan, with special emphasis during childhood, involving interactions between the neuromuscular system and the environment ${ }^{3-}$ ${ }^{5}$. Good levels of MC contribute to enhanced learning of new skills (i.e., faster acquisition of higher performance levels) and a higher motor proficiency on novel motor tasks throughout the lifespan ${ }^{6}$. MC can be developed by situation-specific motor demands ${ }^{7}$, it has been shown to have a sex influence ${ }^{6,8,9}$, and it is expected to be retained in the long term. There is a current growing interest of the scientific community on the role of $\mathrm{MC}$, which has been positively associated with health-related fitness, health, and developmental outcomes ${ }^{10,11}$. Besides, although physical fitness is related to physical activity, both are related to children's $\mathrm{MC}^{2}$.

Indeed, in the last few years, there has been increasing evidence of the importance of MC for developing healthy lifestyles ${ }^{5,12-14}$ and sports participation ${ }^{15,16}$ in children. In 2008, Stodden's model ${ }^{5}$ proposed that physical activities in early childhood would promote the development of MC, which would lead to long-term adherence to physical activity through a variety of exploratory movement experiences. The impact of MC in children's trajectories of physical activity and physical fitness in later life was confirmed by different studies $5,12,17$.

The experiences children have early in life, which influence MC, are dependent on the culture the child lives in. The multiple contexts and affordances that are presented to children, such as home, school, sports environments, or places that afford free play ${ }^{18}$, and the expectations that adults have regarding children's behaviors in those contexts, vary between different cultures ${ }^{19,20}$. The literature shows that cultural diversity should be considered when trying to understand how children develop MC across ages ${ }^{17,21}$. A wide range of studies has compared different motor components in children around the world ${ }^{22-24}$, and there is a growing body of research trying to compare children in different countries and regions ${ }^{17,21,25-27}$. Bardid and colleagues ${ }^{17}$ evaluated the MC of Australian and Belgium children between 6 and 
8 years of age showing that Belgium children outperform Australians on jumping sideways, moving sideways, and hopping for height. Besides, Australian children scored below average on the general MC test. The authors considered that cultural differences in physical activity, physical education $(\mathrm{PE})$, and active transport could help to explain the results. Luz et al. ${ }^{21}$ examined cross-cultural performances on MC and health-related fitness between Portuguese and US children. Results indicated that Portuguese children presented better performances in locomotor performance than US children, but the US children outperformed Portuguese children in throwing and handgrip tests. The authors assumed that cultural differences in PE curricula and sports participation may influence differences in $\mathrm{MC}$ and fitness development in these countries. Despite those studies used different motor assessments, Barid et al. ${ }^{17}$ used the KTK and Luz et al. ${ }^{21}$ used the MCA, both are product-oriented instruments, and provide important results that investigators and PE teachers must consider.

Most cross-cultural studies that address the development of MC highlight the important role of PE classes and sports sessions ${ }^{28}$. For most children, these environments are the opportunity they have to engage in a structured practice that specifically promotes the development of $\mathrm{MC}^{13,29}$. So, differences in performance levels between countries, are probably influenced by the curricular contents of PE classes, the availability of games and sports, and cultural aspects.

Comparisons among different cultural contexts may help researchers to understand the mechanisms for MC development and to elaborate new strategies and policy measures to improve and develop MC in school-aged boys and girls. So, the purpose of this study was to compare the southern Brazilian MC levels with the normative values ${ }^{6}$ of Portuguese schoolchildren. Beyond that, we were also interested in analyzing the differences in $\mathrm{MC}$ between south Brazilian children according to sex and age groups.

\section{Methods}

\section{Participants}

One hundred and forty-eight Brazilian children $(80$ boys, 68 girls - mean age of $7.81 \pm 1.50$ years old) participated in this study. Children were recruited from four different cities and schools (private and public) in south Brazil. All children participated in regular physical education classes during school (two classes per week for approximately 45 min each).

Although in Brazil, nowadays schools follow the National Common Curricular Base (Base Nacional Comum Curricular - BNCC) ${ }^{30}$, the data for this study were collected before the end of the period schools had to adapt to those guidelines (2017). The typical PE classes that our sample has focused was team ball games, recreational activities, gymnastics, Brazilian traditional games, and free play. No children in our sample reported participating in sports activities outside of school.

\section{Procedures}

Participants were evaluated using the Motor Competence Assessment (MCA) instrument ${ }^{6,31}$. The MCA is comprised of six tests distributed for three categories (Locomotor, Stability, Manipulative or Object Control): Standing Long Jump (SLJ), Shuttle Run (SHR), Jumping Sideways (JS), and Shifting Platforms (SP), Ball Kicking Velocity (BKV), and Ball Throwing Velocity (BTV).

In the SLJ test, participants were instructed to perform the jump with maximal effort starting with both feet together. The distance was measured (in centimeters, using a tape measure glued to the ground) as the distance from the starting point to the location of the heel of the foot closest to the starting point after the jump (in centimeters) - the farthest distance of three attempts was used for data analysis.

In the SHR test, children run at maximal speed to a line placed 10 meters apart, picking up a block of wood, running back, and placing it beyond the starting line. Then running back to retrieve the second block and carry it back across the finish line. The final score was the best time of the two trials.

The BKV test required children to kick a soccer ball (circumference, $64.0 \mathrm{~cm}$; mass, $360.0 \mathrm{~g}$ ) against a wall with maximum effort. The BTV test required subjects to use an overarm action to throw a size tennis ball (diameter, $6.5 \mathrm{~cm}$; mass, $57.0 \mathrm{~g}$ ) against a wall with maximum effort. The speed of each attempt (BKV and BTV tests) was measured in meters per second using a radar gun (Pro II STALKER radar gun). The fastest speed of three kicks and the fastest speed of three throws were used for data analyses.

In the JS, participants jump sideways with two feet together over a wooden beam as fast as possible for 15 seconds. Each correct jump scored one point and the best result over two trials was considered. Finally, in the SP test, children were asked to move sideways for 20 seconds using two wooden platforms (25 cm x $25 \mathrm{~cm} \times 2 \mathrm{~cm})$. Each successful transfer from one platform to the other was scored with two points (one point for each step - passing the platform and moving the body to the platform). Participants were given two trials and only the best score was considered. All data were collected between 2017 and 2018.

Three PE teachers, with four years of experience, were trained to collect the data in regularly scheduled classes (each teacher always assessed the same group of tasks). Researchers were trained in the specifications of the assessment's protocols and, at least one of the authors of this study personally supervised every data collection. 
All the evaluations followed the original protocol ${ }^{31}$ and were done in the school gymnasium, always performed by the same evaluators.

Ethical approval for the survey was granted by the Universidade Federal de Santa Maria Ethics Committee (Protocol: 76336117.0.0000.5346). Oral assent was obtained from the participants and written consent from their parents/guardians, before beginning the experiment.

\section{Data analysis}

Normality of the data was confirmed by the Kolmogorov-Smirnov test $(p>0.05)$. Shuttle run scores were inverted due to the nature of the task (higher values represent lower performance). T-scores were calculated for every test on the southern Brazilian sample. Stability, locomotor, and manipulative category MC scores were computed as the sum of the T-scores from the two tasks, and total MC was calculated as the mean of the T-scores for all tests. To investigate the differences in MC according to age and sex, the sample was divided into two age groups: 4- to 7-years-old, and 8- to 11-years-old. A 2x2 ANOVA (sex by age) was performed to analyze the effects of age group, sex, and their interaction for each of the three MCA categories.

For cross-cultural comparison, our sample was then compared to the Portuguese normative values ${ }^{6}$ that used data from two thousand and eighty-seven participants ( 1,102 boys and 985 girls) between 3 and 23 years of age. Brazilian raw scores for each test were transformed according to the Portuguese normative values (percentiles and z-scores). Chi-Square tests were used to compare the distribution of the Brazilian sample with the Portuguese normative quartiles, and t-tests were used to compare between southern Brazilian and Portuguese standardized results on each test. The Statistical Package for Social Sciences (SPSS), version 25.0, was used, adopting an alpha level of significance of $5 \%$.

\section{Results}

Table 1 shows the descriptive values of the MC tests by sex and age groups.

The 2x2 ANOVA overall results (see Figure 1), computed with categories and total MCA mean T-scores, showed main effects of sex and age for all analysis of the southern Brazilian children. More specifically, boys outperformed girls and the older age group outperformed the younger for the different categories: stabilization (sex: $\mathrm{F}(1,143)=23.361, \mathrm{p}<0.001$; age-group: $\mathrm{F}(1,143)=$ 42.228, p < 0.001); locomotion (sex: $\mathrm{F}(1,143)=12.891$, $\mathrm{p}<0.001$; age-group: $\mathrm{F}(1,143)=3.976, \mathrm{p}<0.048)$; manipulation (sex: $\mathrm{F}(1,143)=78.857, \mathrm{p}<0.001$; agegroup: $\mathrm{F}(1,143)=56.142, \mathrm{p}<0.001)$. Differences in total MCA followed the same trend $(\operatorname{sex}: \mathrm{F}(1,143)=38.482$,
Table 1 - Descriptive values (mean and SD) of Brazilian MCA tests by sex and age group.

\begin{tabular}{|c|c|c|c|c|}
\hline & MCA categories & MCA tests & $\begin{array}{l}4 \text { to } 7 \text { years } \\
\text { Mean } \pm \text { SD }\end{array}$ & $\begin{array}{l}8 \text { to } 11 \text { years } \\
\text { Mean } \pm \text { SD }\end{array}$ \\
\hline \multirow{5}{*}{ Boys } & Stabilization & $\mathrm{JS}(\mathrm{n})$ & $19.00 \pm 7.30$ & $28.21 \pm 8.16$ \\
\hline & & $\mathrm{SP}(\mathrm{n})$ & $14.81 \pm 3.47$ & $19.04 \pm 2.77$ \\
\hline & Locomotion & SLJ $(\mathrm{cm})$ & $117.25 \pm 20.85$ & $135.27 \pm 19.86$ \\
\hline & & SHR (s) & $15.76 \pm 2.20$ & $13.08 \pm 1.34$ \\
\hline & Manipulation & BTV (m/s) & $9.26 \pm 3.26$ & $14.73 \pm 2.59$ \\
\hline \multirow{7}{*}{ Girls } & & $\mathrm{BKV}(\mathrm{m} / \mathrm{s})$ & $10.59 \pm 4.30$ & $15.11 \pm 3.73$ \\
\hline & Stabilization & JS (n) & $18.00 \pm 5.74$ & $20.31 \pm 7.40$ \\
\hline & & $\mathrm{SP}(\mathrm{n})$ & $12.66 \pm 3.27$ & $15.73 \pm 3.24$ \\
\hline & Locomotion & $\mathrm{SLJ}(\mathrm{cm})$ & $115.27 \pm 20.33$ & $118.05 \pm 19.14$ \\
\hline & & SHR (s) & $16.27 \pm 1.91$ & $14.86 \pm 1.46$ \\
\hline & Manipulation & $\mathrm{BTV}(\mathrm{m} / \mathrm{s})$ & $7.75 \pm 2.15$ & $9.18 \pm 2.50$ \\
\hline & & $\mathrm{BKV}(\mathrm{m} / \mathrm{s})$ & $7.44 \pm 1.53$ & $9.32 \pm 3.06$ \\
\hline
\end{tabular}

Note: Jumping Sideways (JS), Shifting Platforms (SP), Standing Long Jump (SLJ), Ball Kicking Velocity (BKV), Ball Throwing Velocity (BTV), Shuttle Run (SHR).

$\mathrm{p}<0.001$; age-group: $\mathrm{F}(1,142)=36.848, \mathrm{p}=<0.001)$. Significant interactions between sex and age were found in total motor competence and in all categories of MC. In total motor competence $(\mathrm{F}(1,140)=10.317, \mathrm{p}<0.002)$ and the stability $(\mathrm{F}(1,143)=4.553, \mathrm{p}<0.035)$ and manipulative $(\mathrm{F}(1.143)=14.361, \mathrm{p}<0.001)$ categories, sexes become increasingly different with age. In the locomotor category, the results for girls were lower in the older age group than in the younger, contradicting the usual tendency $(\mathrm{F}(1,143)=9.434, \mathrm{p}<0.003)($ Figure 1$)$.

Table 2 shows the distribution of the Brazilian sample according to the Portuguese quartiles, and chi-square results regarding that distribution comparison. The frequency analysis indicates that southern Brazilian boys are evenly distributed among the Portuguese quartiles of the JS and SP tests. In the other four tests, the Brazilian boys performed significantly better than Portuguese normative values. Regarding girls, Brazilian girls were unevenly distributed among Portuguese quartiles presenting poorer scores in all tests when compared to Portuguese normative values, positioning mostly in the first and second quartiles, except for the SLJ where they positioned mostly in the third and fourth quartiles, performing above Portuguese normative values.

Figure 2 shows the Brazilian mean z-score and 95\% confidence intervals (transformed into the Portuguese normative values) for the six MCA tests in relation to the Portuguese $\mathrm{z}$-scores $(\mathrm{M}=0 ; \mathrm{SD}=1)$. Despite age, when compared to the Portuguese normative reference, Brazilian boys are significantly better in the SLJ, SHR, BTV, and BKV tests. Brazilian girls are significantly worse in the JS, SP, and BTV tests, and significantly better in the SLJ when compared to the Portuguese normative values. 

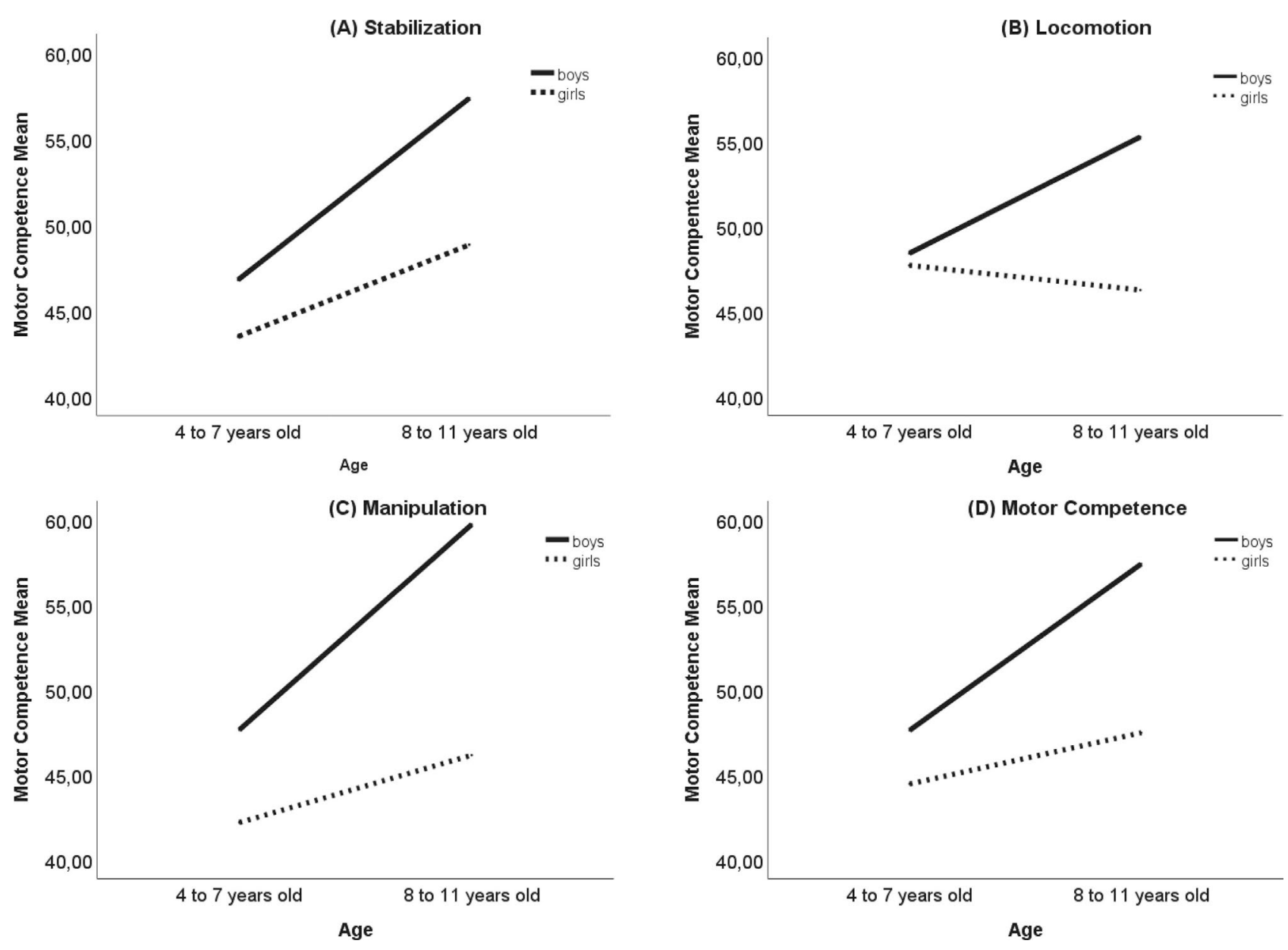

Figure 1 - Mean t-scores for categories and total Brazilian MCA by sex and age group.

There are no differences between Brazilian and Portuguese girls regarding SHR and BKV test.

\section{Discussion}

The primary aim of the present study was to compare the motor competence scores of schoolchildren from south Brazil to the Portuguese normative values. We were also interested in investigating the differences between sex and age groups within the southern Brazilian sample.

Our results showed differences in $\mathrm{MC}$ between the southern Brazilian and the normative values of Portuguese children (see Table 2). Southern Brazilian boys were significantly above the Portuguese normative values for the locomotor and manipulative tasks, whereas no differences were found in the stability tasks. Conversely, southern Brazilian girls showed poorer results compared to Portuguese girls, which raises some concerns. Their results were significantly lower than Portuguese normative values in all tests except in the SLJ where they were above Portuguese normative values. The high values presented in the SLJ by southern Brazilian girls, particularly the younger ones, are a little bit surprising and might be related to spe- cific characteristics of our sample. In fact, these results are worrying if we consider Luz et al. ${ }^{21}$ findings (which uses the same product-oriented instrument as the present study) since the authors showed that Portuguese girls (who outperform Brazilian girls in our study) have lower MC scores than North American girls.

Santos et al. ${ }^{24}$ analyzed the differences in Fundamental Motor Skills (FMS) between distinct cultures, using the TGMD-2 (a process-oriented instrument). The results showed that Portuguese children present lower levels compared with Chinese and US children. The findings also showed associations between the curriculum and the number of children mastering FMS. Despite that, no associations were found regarding sports and the mastery of the related skill. Other studies have reported the influence of cultural differences on children's levels of $\mathrm{MC}^{17,32}$. Despite those studies used different instruments (process-oriented versus product-oriented) the literature shows that there is frequently a correlation between those types of measures ${ }^{33}$. Thus, the results present a trend that investigators and PE teachers must pay close attention to. 
Table 2 - Distribution of the Brazilian sample within the Portuguese normative quartiles and Chi-square results.

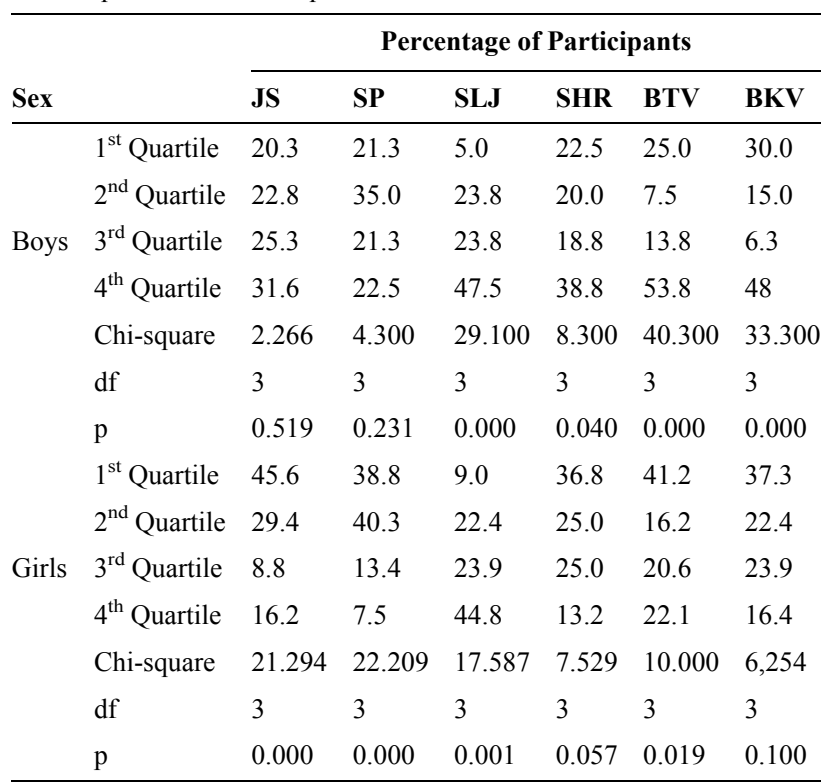

Note: Jumping Sideways (JS), Shifting Platforms (SP), Standing Long Jump (SLJ), Ball Kicking Velocity (BKV), Ball Throwing Velocity (BTV), Shuttle Run (SHR); df (degrees of freedom); p (significance).

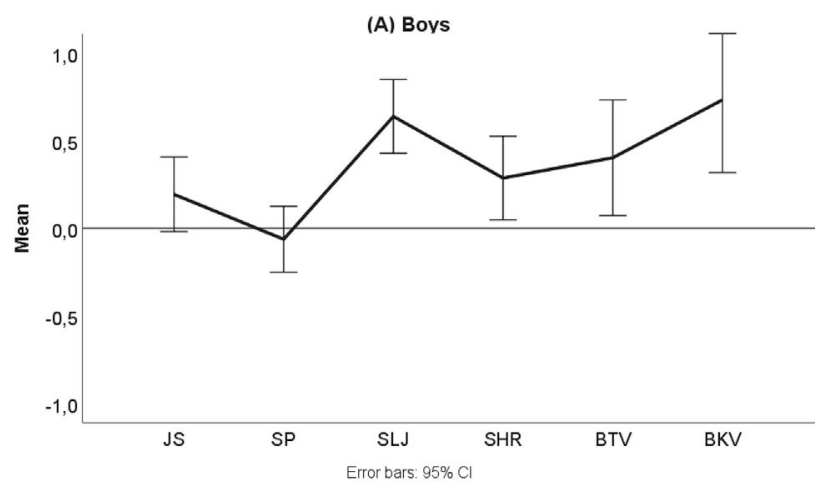

(B) Girls

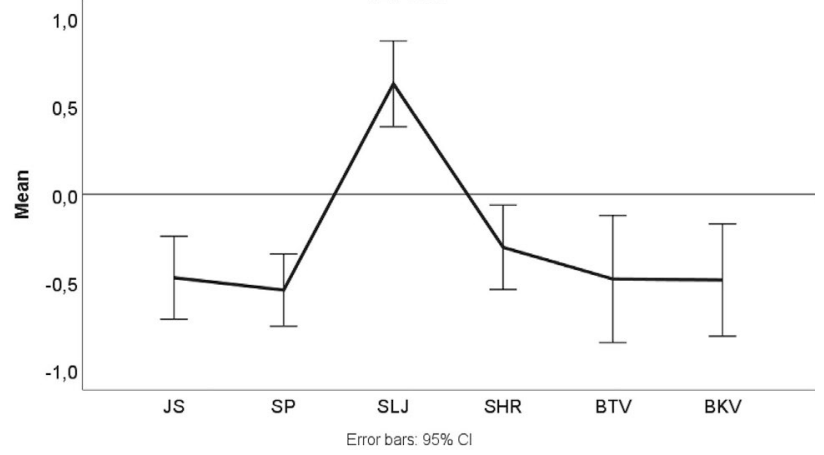

Figure 2 - Brazilian mean z-score and $95 \%$ confidence intervals for the six MCA.

Although in Brazil, schools must follow the $\mathrm{BNCC}^{30}$, the data was collected before the full implementation of the BNCC guidelines. In fact, Azevedo and Pereira $^{34}$ found peculiarities between the PE classes at pri- mary school in Brazil and Portugal. During PE classes, Brazilian girls and boys frequently participate in different $\operatorname{activities}^{35}$. Although the BNCC guidelines make no sex distinctions, since they were not fully implemented when our data was collected, boys tended to play soccer games more frequently, whereas girls, who were less motivated to play, usually preferred to run or play games without contact. On the other hand, in Portugal the curriculum allows children to develop basic motor movements, including outdoor activities ${ }^{34}$. Luz and colleagues ${ }^{21}$, highlight that the PE curriculum in Portuguese schools focuses primarily on FMS and games, on developing a multiplicity of motor skills from the age of 3 , and the activities that girls and boys engage in during classes are usually the same. Therefore, the differences between PE curricula in Brazil and Portugal, southern Brazilian boys and girls having more time to freely play, extracurricular activities, and the culture itself, may have contributed to the differences between southern Brazilian and Portuguese children. Additionally, although MC in Portugal is part of the curriculum, children have less time for motor activities at school each day ${ }^{21}$.

Although southern Brazilian girls have the same number of PE classes as southern Brazilian boys, our results showed that $\mathrm{MC}$ levels are below average compared to their counterparts. Our findings also showed that children's MC increased with age, and boys outperformed girls (see Table 1 and Figure 1), which is in line with the results of previous studies ${ }^{6,21}$. Different studies found similar results, showing that boys present higher MC compared to girls ${ }^{13,36}$. A systematic review conducted by Barnett and colleagues ${ }^{37}$ showed that $\mathrm{MC}$ is related to age (MC increases across time), but also to sex (boys have higher MC than girls), and socioeconomic background (higher MC is associated with higher socioeconomic status). Controversially, Lopes and colleagues ${ }^{38}$ found that boys and girls of all ages showed to have similar MC. Additionally, other studies have reported that boys outperformed girls regarding their motor learning ${ }^{39}$, FMS $^{9}$, and self-perception of motor competence ${ }^{40}$. Kokstejn, Musálek, \& Tufano ${ }^{9}$, using the MABC- 2 test age Band $1^{41}$ (process-oriented instrument) found that, compared to boys of the same age, 3- and 4-year-old girls had greater balance scores (which comprises the jumping tests) and, there were no sex differences for balance scores in 5- and 6-year-olds, showing that girls can perform balance (including jumping) skills in a similar way to boys. Nobre, Valentini, \& Rusidill ${ }^{40}$, emphasized that Brazilian girls have limited opportunities to learn and practice sports skills, presenting poorer motor scores than boys. The literature also indicates that the low levels of MC among Brazilian girls are a widespread problem ${ }^{4244}$. Thus, it is plausible to expect that Brazilian girls may be less encouraged, than boys, to participate in games and physical programs, which in turn negatively affects their MC. 
Cross-cultural comparisons of motor competence

Motor competence has a particularly important role in developing healthy trajectories of life ${ }^{5,12}$ since different studies indicate that good levels of MC during childhood are vital for better levels of children's physical activity participation $^{45-47}$. According to Stodden's model ${ }^{5}$, children and adolescents who perceive themselves as having low motor skill competence will more probably become involved in a negative spiral of disengagement of physical activities. In fact, reduced levels of MC can enhance lower levels of physical activity, physical fitness and perception of motor competence, and high levels of obesity ${ }^{5,12}$. In this model, although it is considered that there is a reciprocal relationship between the variables, $\mathrm{MC}$ is situated as the main variable influencing a positive or negative lifestyle.

Understanding the cultural differences between the PE classes, playgrounds, and other activities that children are involved in can be important to explain our findings, especially the lower levels of southern Brazilian girls MC. The literature shows that girls are less active than boys at different ages and cultures ${ }^{48,49}$, showing that teachers, parents, and all the responsible school staff should pay more attention to this fact. Besides, the expected behaviors for boys and girls have the potential to promote (or not) the development of a set of skills ${ }^{40,50}$. Thus, developmental processes are different regarding sex, and when it comes to $\mathrm{MC}$ during schoolyears, it is important to find strategies to counteract what seems to be a girls' disadvantage, trying to identify which opportunities can be available for girls to develop their MC in the environments they attend to more frequently. Thus, promoting more opportunities for girls can enhance their participation in more active and vigorous activities, increasing MC, levels of physical activity, learning, development, satisfaction, and decreasing obesity levels.

The cross-cultural comparisons between southern Brazilian and Portuguese children may provide further information regarding the children's $\mathrm{MC}$ contributing to understanding the differences and the strengths of the school policies in each country, and the culture itself. Thus, this research can help all school communities to better understand the mechanisms related to the MC performance between countries and genders.

Despite that, the present study showed some limitations. First, we did not assess the number and type of regular activities done by children on their daily routine, which could help us to understand our findings, especially concerning girls in the SLJ test. Thus, despite being important, this study did not analyze how children move in the different systems (e.g.: home, school, neighborhood, etc.) in which they are present on daily basis ${ }^{18}$. Also, the small number of Brazilian schoolchildren, particularly by a wide range of age (4 to 11 years) should be considered. The environments, and the quality of the settings that children regularly attend (i.e., their home, school, and places where they have extracurricular activities), were also not investigated. The quality of these contexts is probably another determinant of children's motor behavior.

\section{Conclusions}

Our results suggest that there is a cultural influence on the levels of MC among southern Brazilian and Portuguese children. Southern Brazilian boys presented better results in four of six of the MC tests (SLJ, SHR, BTV, and BKV), whereas Portuguese girls outperformed the Brazilians in all tests except for the SLJ. The differences between Brazil and Portugal PE curricula, school, free time, and culture probably contribute to these results, providing better opportunities for boys than girls to engage in tasks that develop their MC. In Brazil, girls use their opportunities (to move and play) in a different way than boys to enroll in a variety of movements, games, and physical activities. During recess, girls tend to engage in social activities that do not involve physical activity, instead of playing recreational games, running, or playing team ball games, as boys usually do. The present study provides information on cross-cultural comparison of MC levels in children using the Motor Competence Assessment. Understanding the mechanisms related to the differences in MC performance between countries and genders is important to devise strategies to tackle low levels of MC in target groups that seem to be at greater risk of negative spirals of disengagement of physical activities.

\section{References}

1. Fransen J, D’Hondt E, Bourgois J, Vaeyens R, Philippaerts RM, Lenoir M. Motor competence assessment in children: Convergent and discriminant validity between the BOT-2 Short Form and KTK testing batteries. Res Dev Disabil. 2014;35(6):1375-83.

2. Luz C, Cordovil R, Almeida G, Rodrigues LP. Link between Motor Competence and Health Related Fitness in Children and Adolescents. Sports. 2017;5(4):41.

3. Malina RM. Motor development during infancy and early childhood: overview and suggested directions for research. Int J Sport Heal Sci. 2004;2:50-66.

4. Malina R. Top 10 research questions related to growth and maturation of relevance to physical activity, performance, and fitness [Internet]. Vol. 85, Research Quarterly for Exercise and Sport. Taylor \& Francis; 2014. p. 157-73. Available from: http://dx.doi.org/10.1080/02701367.2014.897592

5. Stodden D, Goodway J, Langendorfer S, Roberton M, Rudisill M, Garcia C, et al. A developmental perspective on the role of motor skill competence in physical activity: An emergent relationship. Quest. 2008;60(2):290-306.

6. Rodrigues LP, Luz C, Cordovil R, Bezerra P, Silva B, Camões $\mathrm{M}$, et al. Normative values of the motor competence assessment (MCA) from 3 to 23 years of age. J Sci Med Sport. 2019;22:1038-43. 
7. Herrmann C, Heim C, Seelig H. Construct and correlates of basic motor competencies in primary school-aged children. J Sport Heal Sci. 2019;8(1):63-70.

8. Flôres F, Menezes K, Katzer J. Influências do sexo na atenção e na aprendizagem de habilidades motoras. J Phys Educ. 2016;27(1):2706.

9. Kokstejn J, Musálek M, Tufano JJ. Are sex differences in fundamental motor skills uniform throughout the entire preschool period? PLoS One. 2017;12(4):1-10.

10. Luz C, Rodrigues LP, De Meester A, Cordovil R. The relationship between motor competence and health-related fitness in children and adolescents. PLoS One. 2017;12(6).

11. Lopes L, Santos R, Coelho-e-Silva M, Draper C, Mota J, Jidovtseff B, et al. A Narrative Review of Motor Competence in Children and Ad- olescents: What We Know and What We Need to Find Out A Narrative Review of Motor Competence in Children and Ad- olescents: What We Know and What We Need to Find Out. Int J Environ Res Public Health. 2021;18(18).

12. Robinson L, Stodden D, Barnett L, Lopes V, Logan S, Rodrigues LP, et al. Motor competence and its effect on positive developmental trajectories of health. Sport Med. 2015;45(9):1273-84.

13. Luz C, Almeida G, Rodrigues LP, Cordovil R. The evaluation of motor competence in typically developing children: An integrative review. J Phys Educ. 2017;28(e2857).

14. Gu X, Thomas K, Chen Y. The Role of Perceived and Actual Motor Competency on Children's Physical Activity and Cardiorespiratory Fitness during Middle Childhood. J Teach Phys Educ. 2017;

15. Ferreira L, Vieira J, Silva P, Chaves R, Fernandes R, Cheuczuk F, et al. The role of sport participation and body mass index in predicting motor competence of school-age children. J Phys Educ. 2019;30(e3024):1-10.

16. Flôres F, Milani M, Copetti F, Luz C, Cordovil R. O impacto da prática do futsal na competência motora de crianças. Motrivivência. 2020;32(63):01-13.

17. Bardid F, Rudd J, Lenoir M, Polman R, Barnett L. Crosscultural comparison of motor competence in children from Australia and Belgium. Front Psychol. 2015;6(July):1-8.

18. Flôres F, Rodrigues LP, Copetti F, Lopes F, Cordovil R. Affordances for Motor Skill Development in Home, School, and Sport Environments: A Narrative Review. Percept Mot Skills. 2019;126(3):003151251982927.

19. Silva S, Flôres F, Corrêa S, Cordovil R, Copetti F. Mother's Perception of Children's Motor Development in Southern Brazil. Percept Mot Skills. 2017;124(1):72-85.

20. Cordovil R, Santos C, Barreiros J. Perceiving children's behavior and reaching limits in a risk environment. J Exp Child Psychol. 2012;111(2):319-30.

21. Luz C, Cordovil R, Rodrigues LP, Gao Z, Goodway J, Sacko RS, et al. Motor competence and health-related fitness in children: A cross-cultural comparison between Portugal and the United States. J Sport Heal Sci. 2019;8 (2):130-6.

22. Saraiva L, Rodrigues LP, Cordovil R, Barreiros J. Motor profile of Portuguese preschool children on the Peabody
Developmental Motor Scales-2: A cross-cultural study. Res Dev Disabil. 2013;34(6):1966-73.

23. Gosso Y, De Lima M, Morais SE. Pretend play of Brazilian children: A Window Into Different Cultural Worlds. J Cross Cult Psychol. 2007 Sep;38(5):539-58.

24. Santos F, Pacheco M, Basso L, Tani G. A comparative study of the mastery of fundamental movement skills between different cultures. Motricidade. 2016;12(2):116-26.

25. Haga M, Tortella P, Asonitou K, Charitou S, Koutsouki D, Fumagalli G, et al. Cross-Cultural Aspects: Exploring Motor Competence Among 7- to 8-Year-Old Children From Greece, Italy, and Norway. SAGE Open. 2018;8(2).

26. Brian A, Bardid F, Barnett L, Deconinck F, Lenoir M, Goodway J. Actual and perceived motor competence levels of Belgian and United States preschool children. J Mot Learn Dev. 2018;6(s2):S320-S336.

27. Guimarães E, Baxter-Jones A, Pereira S, Garbeloto F, Freitas D, Janeira MA, et al. Patterns of physical performance spurts during adolescence: a cross-cultural study of Canadian, Brazilian and Portuguese boys. Ann Hum Biol [Internet]. 2020;47(4):346-54. Available from: https://doi.org/ 10.1080/03014460.2020.1781928

28. Morgan PJ, Barnett L, Cliff DP, Okely AD, Scott HA, Cohen KE, et al. Fundamental movement skill interventions in youth: A systematic review and meta-analysis. Pediatrics. 2013;peds. 2013-1167.

29. McKenzie T, Lounsbery M. Physical Education Teacher Effectiveness in a Public Health Context. Res Q Exerc Sport. 2013 Dec;84(4):419-30.

30. BRASIL. Base Nacional Comum Curricular. Ministério da Educação. Secretaria da Educação Básica Brasil; 2016.

31. Luz C, Rodrigues LP, Almeida G, Cordovil R. Development and validation of a model of motor competence in children and adolescents. J Sci Med Sport. 2015;19:568-72.

32. Chow S, Henderson S, Barnett L. The Movement Assessment Battery for Children: A comparison of 4-year-old to 6year-old children from Hong Kong and the United States. Am J Occup Ther. 2001;55(1):55-61.

33. Hulteen RM, True L, Pfeiffer KA, Hulteen RM, True L, Differences KAP. Differences in associations of productand process-oriented motor competence assessments with physical activity in children. J Sports Sci [Internet]. 2020;38 (4):375-82. Available from: https://doi.org/10.1080/ 02640414.2019.1702279

34. Azevedo E, Pereira B. As competências e as componentes essenciais da Educação Física no I $^{\mathrm{O}}$ Ciclo Escolar de Portugal e do Brasil. Rev Mackenzie Educ Física e Esporte. 2009;6(1):69-87.

35. Nunes M. O engajamento de meninos e meninas nas aulas de educação física. Universidade Federal de do Rio Grande do Sul; 2010.

36. Quitério A, Costa J, Martins M, Martins J, Onofre M, Gerlach E, et al. Educação física: Avaliação das competências motoras em alunos de seis anos, do primeiro ano de escolaridade. Retos. 2017;31(January):259-63.

37. Barnett L, Lai S, Veldman S, Hardy L, Cliff D, Morgan P, et al. Correlates of gross motor competence in children and adolescents: a systematic review and meta-analysis. Sport Med. 2016;46(11):1663-88. 
38. Lopes V, Saraiva L, Gonçalves C, Rodrigues LP. Association Between Perceived and Actual Motor Competence in Portuguese Children”. J Mot Learn Dev. 2017;

39. Flôres F, Menezes K, Katzer J. Influences of gender on attention and learning of motor skills. J Phys Educ. 2016;27 (1):e2706.

40. Nobre F, Valentini N, Rusidill M. Applying the bioecological theory to the study of fundamental motor skills. Phys Educ Sport Pedagog. 2020 Jan 2;25(1):29-48.

41. Henderson S, Sugden D, Barnett L. Movement Assessment Battery for Children-2 (MABC-2): Examiner's manual. London: Pearson Assessment; 2007.

42. Cohen K, Morgan P, Plotnikoff R, Callister R, Lubans D. Fundamental movement skills and physical activity among children living in low-income communities: A cross-sectional study. Int J Behav Nutr Phys Act. 2014 Apr 8;11(1).

43. Spessato B, Gabbard C, Valentini N, Rudisill M. Gender differences in Brazilian children's fundamental movement skill performance. Early Child Dev Care. 2013;183(7):91623.

44. Ferreira L, Gabbard C, Vieira J, Tamplain P. Associations Between the Developmental Coordination Disorder Questionnaire-Brazilian Version (DCDQ-BR) and Motor Competence in School-Age Children. Phys Occup Ther Pediatr. 2020;40(2):121-33.

45. Clark JE, Metcalfe JS. The mountain of motor development: A metaphor. Mot Dev Res Rev. 2002;2:163-90.

46. Logan S, Kipling W, Getchell N, Pfeiffer K, Robinson L. Relationship Between Fundamental Motor Skill Competence and Physical Activity During Childhood and Adolescence: A Systematic Review. Kinesiol Rev. 2015;4(4):41626.
47. Lubans D, Morgan P, Cliff D, Barnett L, Okely A. Review of the benefits associated with fundamental movement skill competency in youth. Sport Med. 2010;40(12):1019-35.

48. Tsuda E, Goodway JD, Famelia R, Brian A, Tsuda E, Goodway JD, et al. Research Quarterly for Exercise and Sport Relationship Between Fundamental Motor Skill Competence, Perceived Physical Competence and Free-Play Physical Activity in Children Relationship Between Fundamental Motor Skill Competence, Perceived Physical. Res Q Exerc Sport. 2019;0(0):1-9.

49. Goodway J, Robinson L, Crowe H. Gender differences in fundamental motor skill development in disadvantaged preschoolers from two geographical regions. Res Q Exerc Sport. 2010;81(1):17-24.

50. Bronfenbrenner U, Morris PA. The bioecological model of human development. Handb child Psychol, 14, 12007.

\section{Corresponding Author}

Fábio Saraiva Flôres. Avenida Jorge Peixinho, n. ${ }^{\circ} 30$, Quinta da Arreinela, 2805-059 Almada, Portugal.

E-mail: fabio.flores@almada.ipiaget.pt.

Manuscript received on October 7, 2020

Manuscript accepted on April 29, 2021

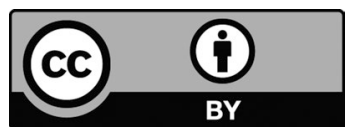

Motriz. The Journal of Physical Education. UNESP. Rio Claro, SP, Brazil - eISSN: 1980-6574 - under a license Creative Commons - Version 4.0 